\title{
La Opríchnina en los tiempos de Iván IV
}

\author{
Tanee V. Rojas \\ (tavairo@hotmail.com)
}

SOROKIN, Vladimir (2008). El día del Oprichnik. Editorial Alfaguara, 240 pp.

Para entender un poco el texto de Sorokin, es importante tener en cuenta lo que fue la Opríchnina en los tiempos de Iván IV el Terrible. Esta fue una fuerza "policial" establecida por Iván en 1565, quien en ese momento era el zar de Rusia y gozaba de poderes absolutos en parte del territorio, pues la otra aún conservaba la antigua administración zarista. Esta guardia era bastante violenta y fue creada con el fin de cumplir la voluntad de Iván (en parte del territorio), quien intentaba aniquilar a todos aquellos que se opusieran a él, y de tal manera, sembrar miedo para tener cierto control sobre el territorio.

Sorokin, por su parte, trae de vuelta a los oprichniks pero esta vez, dentro del marco de una nación llamada la Nueva
Rusia, situada en el año 2027, la cual según el texto, se encuentra aislada por una Gran Muralla y cuyo máximo gobernante es el Soberano, quien también goza de poderes absolutos, por lo cual se le debe rendir cuenta de todo lo referente a la cuestiones de la Nueva Rusia.

Uno de los oprichniks es Komyaga, en el que se basa Sorokin relatando un día de trabajo, con el fin de mostrar la labor de los oprichniks en esa Rusia. Él está bajo el mando de Padre, quien es al parecer un hombre muy sabio debido a sus experiencias y se encarga de la formación de todos los oprichniks. Pero, ¿qué es en realidad lo que quiere evidenciar Sorokin en esta obra? En la obra se tocan distintos temas: la prohibición de algunas sustancias, las victimas del Estado ruso, el 
control del monarca sobre la literatura y los artículos para vender en los quioscos rusos, y finalmente, la construcción de la Gran Muralla.

Los oprichniks, como primer tema a discutir, son un grupo bastante privilegiado por el hecho de que trabajan para el Soberano: cumpliendo sus órdenes y ayudándole administrar el territorio. Gozan de diferentes placeres que están prohibidos para el resto de los ciudadanos, ya que según el Soberano, estos placeres son un mal para el Estado y no lo benefician para nada. El caballo, la acidez y las setas, y sobre todo los pececillos, son las sustancias que obtienen a cambio de acostarse con una reconocida bailarina, la favorita de la Soberana. Todos estas sustancias producen una sensación de nerviosismo y descontrol, que impiden que se cumpla activamente con el trabajo de cada quien, y por tal motivo son prohibidas para el pueblo.

Ellos en realidad ejercen su poder como desean. Dicho esto, se puede abarcar el segundo tópico: las victimas del Estado ruso. Este punto se evidencia en situaciones como la cacería del noble (a quien ahorcaron y le destruyeron todas sus cosas), Igualmente, la violación de la mujer del Noble sustenta la idea del abuso de poder del Estado de la Nueva Rusia. Los oprichniks también ejercieron suficiente presión para exiliar a familias, una vez que habían asesinado algunos de sus miembros.

Respecto a la literatura, se evidencia como en un supuesto 2027, el Soberano, practica control sobre el flujo de publicaciones y material escrito . Es él quien decide que se puede leer en la Nueva Rusia y qué no; sin embargo, su dominio no se detiene ahí, el teatro, los eventos, y todo lo que se refiera a manifestaciones culturales, son también vigilados por él con la ayuda de los oprichniks. Para aprobar una obra de teatro que se utilizará en algún evento, alguno de los oprichniks tiene que ir a verla y decidir si se puede o no utilizar, y si se tiene que cambiar alguna parte de la presentación, de tal manera que todo se haga como el soberano desea, y mostrando los aspectos positivos más importantes de la historia de Rusia, y que hagan ver al Soberano como lo mejor que le ha ocurrido a Rusia.

El cuarto punto no se aleja mucho del tercero. También se controlan los artículos a vender en los quioscos rusos, que fueron creados después de que el padre del Monarca decretó liquidar todos los supermercados foráneos, y que cada uno 
de estos quioscos tenga dos variedades de cada producto con el fin de que la población tuviera una fácil elección, pero entre dos productos rusos, que no estuvieran lejos de sus costumbres y tradiciones, y que de acuerdo con esto, se tuviera un pueblo conforme y satisfecho.

El quinto y último punto es aquel de el dela Gran Muralla, con lo cual quiero citar unas palabras de Padre hacia los oprichniks en una reunión cuando expresa la razón por la cual se construyó el Muro:

"Fue para amparar la fe en Cristo como un tesoro inmaculado, ¿vale? Puesto que solo nosotros los ortodoxos, hemos conservado en la Tierra la Iglesia en su cualidad de cuerpo de Cristo, la una, santa, ecuménica, apostólica e impecable Iglesia, ¿vale? Puesto que tras el segundo concilio de Nicea solo nosotros glorificamos al Señor de manera correcta, ya que somos ortodoxos, ya que el derecho de glorificar al Señor de manera correcta nadie nos lo ha quitado, ¿vale? Puesto que nosotros no renunciamos al principio conciliar, o sea, que nos mantuvimos con un par en la Tradición Carismática que guarda el auténtico sentido de la fe de los padres, de los santos iconos, la Virgen María, la Santísima Trinidad, el Espiritu Santo, señor y dador de vida que procede del Padre y del Hijo, que con el Padre y el Hijo recibe una misma adoración y gloria, y que hablo por los profe- tas, ¿vale? Ya que rechazamos nosotros todo lo obsceno, herético, blasfemo: el maniqueísmo, el monofisismo, el monofiletismo y el loqueseaísmo, ¿vale? Puesto que para quien la Iglesia no es la madre, tampoco Dios puede ser el padre, ¿vale? Puesto que Dios, por su naturaleza, está por encima de toda comprensión ¿vale? Puesto que todos los padres ortodoxos, todos, son los herederos de Pedro, que papa ni que obleas en vinagre, ¿vale? Puesto que no existe el purgatorio, solo hay infierno y paraíso, ¿vale? Puesto que el hombre es mortal y por eso peca, ¿vale? Puesto que Dios es la luz, ¿vale? Puesto que nuestro Salvador se ha hecho hombre para que nosotros, los lobos hocicosos, nos hiciéramos dioses, ¿vale? iEs por eso por lo que construyo el Monarca nuestra Gran Muro, para aislarse del hedor a incredulidad, de los ciberpunkies malditos, de los sodomitas, de los católicos, de los melancólicos, de los budistas, de los sádicos, de los satánicos, de los marxistas, de los megaonanistas, de los fascistas, de los pluralistas y de los ateistas! ;Porque la fe, mis lobos hocicosos, no es lo mismo que el billetero! ¡No es el caftán de brocado! ;La fe, mis retumbantes inocentones, es el pozo del agua manantial, pura, trasparente, calmosa, sencilla, fuerte y copiosa!" (Sorokin, 2006:151-152)

Esta Nueva Rusia está separada del resto del mundo con el fin de no mezclar sus creencias e ideales con otros países, 
de que estos no influyan en su manera de gobernar y ver las cosas, y sobre todo en lo que respecta a la religión, que como se evidencia en la cita, es muy importante, es fundamental.

Para concluir, pienso que Sorokin lo que trató de hacer con este libro fue hablar de una Rusia futurista que no está muy lejos de lo que se ha vivido anteriormente en Rusia: censuras en muchos sentidos, privilegios para quienes trabajan para el zar, castigos terribles para quienes se atreven a desafiarlo y se oponen a él. Una Rusia futurista, pero que igualmente sigue aferrada a una época imperial, de la cual hacen parte las élites oligarcas, guardias "aterradores" y un pueblo "sumiso" que aparenta estar de acuerdo con todo $\mathrm{y}$ estar agradecido. Y es que Sorokin cree que esto es lo que posiblemente pasa con la Rusia actual bajo el gobierno de Putin.

Como lo dice él mismo en una entrevista sobre el libro, criticando el actual régimen: "Rusia está retornando a la Edad Media, y que lo que vivimos ahora no es una fascistización sino una feudalización. Vamos hacia una Rusia feudal donde las autoridades se convierten nuevamente en algo absoluto, incomprensible para el pueblo y que no toma en cuenta para nada al pueblo".

\section{Bibliografía}

SOROKIN, Vladimir, El día del Oprichnik, Editorial Alfaguara, Madrid, 2006.

OPRICHNINA. (s.f.). En Wikipedia, la enciclopedia libre. Recuperado el 16 de Mayo de 2013, desde: http://es.wikipedia.org/wiki/Opr\%C3 $\%$ ADchnina

FERNÁNDEZ, R. (2008, 31 de Mayo). La pesadilla literaria de $\mathrm{Pu}-$ tin. En Diario El País. Recuperado el 17 de Mayo de 2013 desde, http:// elpais.com/diario/2008/01/31/cultura/1201734001_850215.html 
